\title{
Penyuluhan Pengurus Bumdes untuk Meningkatkan Kesejahteraan Masyarakat Desa Mekarmukti Kecamatan Buahdua Kabupaten Sumedang
}

\section{Counseling of Bumdes Management Board to Improve the Welfare of Mekarmukti Village Society, Buahdua District, Sumedang Regency}

\author{
Edi Setiawan \& Amelia Lestari Fauzy \\ Sekolah Tinggi Ilmu Administrasi Sebelas April Sumedang, Indonesia \\ Diterima: 23 September 2019 ; Disetujui: 05 Maret 2020 ; Dipublish: 09 Maret 2020 \\ *Corresponding Email : edisetiawan.stia@gmail.com./Fauzyame169@gmail.com
}

\section{Abstrak}

Pada saat ini, Sumber Daya Manusia Masyarakat Indonesia masih perlu ditingkatkan. Karenanya, Pengabdian Kepada Masyarakat ini mengambil objek berupa penyuluhan dengan subjeknya adalah anggota Bumdes Mekarmukti Kecamatan Buahdua Kabupaten Sumedang dengan harapan pengurus Bumdes dapat berdaya guna dan berhasil guna. Kebingungan pengurus bumdes tentang apa yang harus dilakukan dalam mengelola Bumdes adalah permasalahan utama dalam pelaksanaan pengabdian ini. Selain daripada itu, Desa Mekarmukti yang didominasi oleh lahan pertanian dipersepsikan sebagai lahan yang terbatas dalam pengelolaan bumdes. One vilage one product adalah salah satu program Pemerintah Kabupaten Sumedang dalam rangka meningkatkan kesejahteraan masyarakat yang dimulai dari pemerintahan desa. Kabupaten Sumedang akan maju jika seluruh daerahnya mampu memaksimalkan potensi yang ada. Keberagaman baik dari segi sumber daya alam maupun sosial dan budaya merupakan sebuah modal competitive advantages bagi Kabupaten Sumedang untuk bangkit. Perekonomian masyarakat akan bangkit menjadi perekonomian yang kuat, tangguh dan terhormat jika indeks daya saing berada pada tingkat yang tinggi. Paradigma bekerja bersama masyarakat adalah metode yang dipakai untuk lebih menerapkan prinsip partisipatif dan kemandirian bagi pengurus Bumdes. Hasil yang diperoleh berupa meningkatnya motivasi pengurus dalam mengelola bumdes, terbukanya mindset bahwa apa pun bisa dijadikan bahan untuk usaha Bumdes, kerjasama antara pengurus bumdes dan aparat pemerintahan desa dengan DPMPD kabupaten Sumedang sebagai Stakeholder dalam pembinaan desa semakin kuat.

Kata kunci: Penyuluhan Bumdes

\begin{abstract}
At this time, the Indonesian Community's Human Resources still need to be improved. Therefore, this Community Service takes an object consisting of downloading with the subject being a member of the Bumdes Mekarmukti Buahdua District, Sumedang Regency in the hope that the Bumdes management will be effective and effective. The bumdes management's confusion about what had to be done in the Bumdes was the main difficulty in carrying out this dedication. In addition, Mekarmukti Village which was allocated by agricultural land was prepared as limited land in the management of village bumdes. One village of one product is one of the Sumedang District Government programs in order to improve the welfare of the community that starts from the village administration. Sumedang Regency will advance if it reaches its region able to maximize existing potential. Success both in terms of natural resources and social and cultural capital is a competitive advantage for Sumedang Regency to rise. The people's economy will increase to become strong, resilient and powerful if the competitiveness index is high. The paradigm of working with the community is a method used to further apply participatory principles and independence to Bumdes administrators. The results obtained from supporting the motivation of administrators in the bumdes, the opening of any mindset that can be used as material for the Bumdes effort, the collaboration between the bumdes management and village government officials with the DPMPD of Sumedang district as a Stakeholder in village coaching is getting stronger.
\end{abstract}

Keywords: Counseling Bumdes

How to cite: Setiawan E, \& Fauzy L, (2020). Penyuluhan Pengurus Bumdes untuk Meningkatkan Kesejahteraan Masyarakat Desa Mekarmukti Kecamatan Buahdua Kabupaten Sumedang. Pelita Masyarakat: Jurnal Pengabdian Masyarakat, 1(2): 64-75 


\section{PENDAHULUAN}

Melalui program Kuliah Kerja Nyata yang diselenggarakan oleh perguruan tinggi yang diantaranya adalah STIA Sebelas April Sumedang, Pemerintah Kabupaten menetapkan program "One Vilage One Product" dengan leading sector Dinas Pemberdayaan Masyarakat dan Desa (DPMPD) untuk diimplementasikan oleh perguruan tinggi di desa-desa yang ada di Kabupaten Sumedang. Hal ini sangat disadari bahwa masih ada beberapa desa yang belum mampu memunculkan produknya sebagai bagian dari peningkatan kesejahteraan masyarakat. Permasalahan utama muncul dari sumber daya manusia yang masih belum memahami tentang proses pengelolaan Badan Usaha Milik Desa (Bumdes) sehingga mobilitas bumdes menjadi terhambat.

Program Kuliah Kerja Nyata (KKN), merupakan kegiatan lapangan bagi mahasiswa yang menempuh bagian akhir dari program pendidikan S-1/D-4/Sarjana Terapan. Program ini sebenarnya bersifat wajib bagi semua mahasiswa, karena program ini mampu mendorong empati dan simpati mahasiswa terhadap permasalahan masyarakat, dan dapat memberikan sumbangan bagi penyelesaian persoalan yang ada di masyarakat. Program KKN memberikan kesempatan bagi mahasiswa untuk mendapatkan pembelajaran di lapangan yang sebelumnya tidak didapatkan di bangku kuliah. Selain itu kegiatan KKN menjadi bentuk nyata kontribusi Perguruan Tinggi (PT) bagi masyarakat industri, pemerintah daerah dan kelompok masyarakat yang ingin mandiri secara ekonomi maupun sosial. Program KKN ini mensyaratkan Dosen Pembimbing Lapangan (DPL) dan mahasiswa berperan aktif dalam mengetahui permasalahan yang ada dan memberikan solusi atas permasalahan tersebut dalam kurun waktu selama 1 hingga 2,5 bulan di lapangan dengan konsep "bekerja bersama masyarakat" sebagai pengganti konsep "bekerja untuk masyarakat”.

Dalam upaya meningkatkan citra dan mutu kegiatan KKN, maka pelaksanaan KKN dirancang lebih kontekstual dengan mengubah paradigma pembangunan menjadi paradigma pemberdayaan. Revitalisasi Kuliah Kerja Nyata (KKN) menjadi Kuliah Kerja Nyata-Pembelajaran dan Pemberdayaan Masyarakat (KKN-PPM) Perguruan Tinggi (PT) di seluruh Indonesia sangatlah penting untuk dilakukan.

Pada pelaksanaan KKN Tahun 2019, STIA Sebelas April Sumedang menetapkan 13 Desa di Wilayah Kecamatan Buahdua sebagai Mitra Pengabdian Kepada Masyarakat yang salah satunya adalah Desa Mekarmukti. Penetapan mitra PKM tersebut berdasarkan saran dan pendapat unsur pimpinan STIA Sebelas April Sumedang serta 
Edi Setiawan \& Amelia Lestari Fauzy, Penyuluhan Pengurus Bumdes untuk Meningkatkan Kesejahteraan Masyarakat Desa Mekarmukti Kecamatan Buahdua Kabupaten Sumedang

berkaitan dengan program Pemerintah Kabupaten Sumedang untuk membantu masyarakat desa melalui penataan administrasi Badan Usaha Milik Desa (BUMDes) sehingga terbentuklah Mitra PKM yaitu sebagai berikut:

Tabel 1.

Mitra Pengabdian Kepada Masyarakat

\begin{tabular}{lll}
\hline Kategori Mitra, Tipe Mitra & Mitra & Dana \\
\hline Mitra Sasaran & Winata & \multirow{2}{*}{ Mandiri } \\
\hline
\end{tabular}

Dalam rangka meningkatkan kesejahteraan masyarakat yang dimulai dari pemerintahan desa, Bupati Sumedang menetapkan petunjuk teknis pendirian, pengelolaan dan pembubaran Badan usaha milik desa (Peraturan Bupati Sumedang, 2018).

Dalam peraturan tersebut dikatakan bahwa Badan Usaha Milik Desa selanjutnya disebut BUM Desa adalah badan usaha yang seluruh atau sebagian besar modalnya dimiliki oleh Desa melalui penyertaan secara langsung yang berasal dari kekayaan Desa yang dipisahkan guna mengelola aset, jasa pelayanan, dan usaha lainnya untuk sebesarbesarnya kesejahteraan masyarakat desa. Usaha desa tersebut meliputi jenis usaha yang berupa pelayanan ekonomi desa seperti usaha jasa, penyaluran sembilan bahan pokok, perdagangan hasil pertanian, industri dan kerajinan rakyat.

Angka Keluarga Pra Sejahtera di Kabupaten Sumedang Tahun 2017 (BPS Kabupaten Sumedang, 2018) tergolong dalam kategori rendah dengan data sebagai berikut:

Tabel 2.

Jumlah Keluarga Menurut Kecamatan dan Klasifikasi Keluarga di Kabupaten Sumedang, 2017

\begin{tabular}{|l|l|l|l|l|l|}
\hline \multirow{2}{*}{ No. } & \multirow{2}{*}{ Kecamatan } & \multicolumn{2}{|l|}{ Keluarga } & \multirow{2}{*}{ Jml } \\
\cline { 3 - 5 } & & Pra Sejahtera & Sejahtera I & Sejahtera II & \\
\hline 010 & Jatinangor & 986 & 9.991 & 14.350 & 25.327 \\
\hline 020 & Cimanggung & 1.640 & 10.147 & 13.182 & 24.969 \\
\hline 030 & Tanjungsari & 1.373 & 3.767 & 18.216 & 23.356 \\
\hline 031 & Sukasari & 584 & 2.873 & 7.697 & 11.154 \\
\hline 032 & Pamulihan & 1.169 & 7.071 & 11.796 & 20.036 \\
\hline 040 & Rancakalong & 408 & 1.374 & 11.915 & 13.697 \\
\hline 050 & Sumedang Selatan & 491 & 2.133 & 22.374 & 24.998 \\
\hline 06o & Sumedang Utara & 1.125 & 10.654 & 18.224 & 30.003 \\
\hline 061 & Ganeas & 203 & 893 & 7263 & 8.359 \\
\hline 070 & Situraja & 373 & 3.150 & 10.301 & 13.824 \\
\hline 071 & Cisitu & 187 & 2.079 & 7.552 & 9.818 \\
\hline 080 & Darmaraja & 490 & 4.998 & 6.546 & 12.034 \\
\hline 090 & Cibugel & 267 & 2.998 & 4.173 & 7.438 \\
\hline 100 & Wado & 534 & 6.197 & 7.007 & 13.738 \\
\hline 101 & Jatinunggal & 623 & 8.091 & 6.297 & 15.011 \\
\hline 111 & Jatigede & 325 & 3.071 & 5.021 & 8.417 \\
\hline
\end{tabular}


Sumber:(BPS Kabupaten Sumedang, 2018)

\begin{tabular}{|l|l|l|l|l|l|}
\hline 120 & Tomo & 388 & 1.367 & 6.387 & 8.142 \\
\hline 130 & Ujungjaya & 488 & 1.379 & 9.402 & 11.269 \\
\hline 140 & Conggeang & 308 & 2.635 & 8.170 & 11.113 \\
\hline 150 & Paseh & 318 & 1.933 & 10.632 & 12.883 \\
\hline 160 & Cimalaka & 541 & 4.495 & 14.710 & 19.746 \\
\hline 161 & Cisarua & 321 & 1.654 & 4.938 & 6.913 \\
\hline 170 & Tanjungkerta & 429 & 3.170 & 8.389 & 11.988 \\
\hline 171 & Tanjungmedar & 295 & 2.163 & 7.007 & 9.465 \\
\hline 180 & Buahdua & 425 & 4.320 & 7.453 & 12.198 \\
\hline 181 & Surian & 155 & 470 & 3.854 & 4.479 \\
\hline Sumedang & 14.446 & 103.073 & 252.856 & 370.375 \\
\hline
\end{tabular}

Rendahnya angka keluarga pra sejahtera sangat memungkinkan bagi Kabupaten Sumedang untuk mewujudkan keluarga yang sejahtera secara keseluruhan. Karenanya, perlu kerjasama berbagai pihak untuk mewujudkan harapan tersebut sebagai bagian dari Visi Kabupaten Sumedang "SIMPATI".

Jumlah Bumdes di Kabupaten Sumedang (Jabarprov.go.id, 2017) berdasarkan laporan Kepala Dinas Pemberdayaan Masyarakat \& Desa (PMD) Teddy Mulyono, Kab. Sumedang telah memiliki 81 BUMDes aktif dari total keseluruhan 165 BUMDes yang sudah terbentuk di wilayah Pemkab Sumedang. Dari 270 desa di Sumedang, baru ada sekitar 81 BUMDes aktif, dan tentu ini harus dianalisis juga karena keberadaan BUMDes adalah wajib.

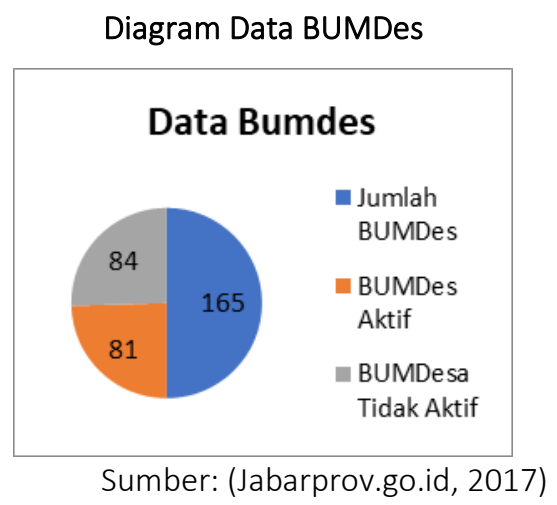

Dari 84 BUMDes tidak aktif tersebut permasalahan yang dialami adalah sumber daya manusia. Apabila dilihat dari perspektif ilmu administrasi, Sumber Daya Manusia atau biasa disebut dengan "Man", adalah salah satu unsur yang sangat menentukan dalam roda organisasi. Hal ini dialami oleh BUMDes Mekarmukti, dimana para pengurus BUMDes sangat memerlukan informasi tentang tata cara pengelolaan BUMDes sehingga diperlukan dinas terkait yang dalam hal ini adalah DPMPD Kabupaten Sumedang untuk menyampaikan hal-hal pokok dalam pengelolaan BUMDes sebagai salah satu penggerak perekonomian desa. 
Sebagai sebuah organisasi, BUMDes tentu memerlukan kualitas manusia yang handal, kompeten, dan berkualitas agar proses administrasi bisa berjalan dengan lancar, tertib, efektif, efisien yang bermuara kepada berjalannya BUMDes dalam memberikan kontribusi melalui proses usaha untuk mensejahterakan masyarakat, bangsa, dan negara pada lingkup pemerintahan desa.

Manusia merupakan penggerak yang beraktivitas agar tujuan organisasi bisa tercapai (Silalahi, 2011) yang dengan inovasi, motivasi, dan kreativitasnya menjalankan fungsi-fungsi administrasi yang dimulai dari perencanaan sampai dengan proses evaluasi. Tanpa manusia maka tidak akan ada kegiatan-kegiatan administrasi.

\section{ANALISIS SITUASIONAL}

Badan Usaha Milik Desa selanjutnya disebut BUM Desa menurut (Peraturan Bupati Sumedang, 2018) Pasal 1 Ayat (9) adalah badan usaha yang seluruh atau sebagian besar modalnya dimiliki oleh Desa melalui penyertaan secara langsung yang berasal dari kekayaan Desa yang dipisahkan guna mengelola aset, jasa pelayanan, dan usaha lainnya untuk sebesar-besarnya kesejahteraan masyarakat Desa.

Dasar pemikiran pembentukan BUMDes adalah untuk meningkatkan kemampuan keuangan pemerintah desa dan meningkatkan pendapatan masyarakat yang dikelola dengan semangat kekeluargaan dan kegotongroyongan.

Adapun tujuan dari pendirian BUMDes adalah :

1. meningkatkan perekonomian Desa;

2. mengoptimalkan aset Desa agar bermanfaat untuk kesejahteraan Desa;

3. meningkatkan usaha masyarakat dalam pengelolaan potensi ekonomi Desa;

4. mengembangkan rencana kerja sama usaha antar desa dan/atau dengan pihak ketiga;

5. menciptakan peluang dan jaringan pasar yang mendukung kebutuhan layanan umum warga;

6. membuka lapangan kerja;

7. meningkatkan kesejahteraan masyarakat melalui perbaikan pelayanan umum, pertumbuhan dan pemerataan ekonomi Desa; dan

8. meningkatkan pendapatan masyarakat Desa dan Pendapatan Asli Desa.

Ada beberapa pertimbangan yang harus diperhatikan dalam mendirikan BUMDes, diantaranya adalah:

1. Atas inisiatif Pemdes dan/atau masy berdasarkan musyawarah warga desa.

2. Adanya potensi usaha ekonomi masyarakat desa.

3. Sesuai dgn kebutuhan masy, terutama dlm pemenuhan kebutuhan pokok. 
4. Tersedia sumber daya desa yg blm dimanfaatkan scr optimal terutama kekayaan desa.

5. Tersedianya SDM yg mampu mengelola badan usaha sebagai aset penggerak perekonomian masy desa.

6. Ketersediaan modal.

Berdasarkan Data Desa Mekarmukti tahun 2019, jumlah penduduknya adalah sebagai berikut:

$\begin{array}{ll}\text { Laki-laki } & : 1236 \text { jiwa } \\ \text { Perempuan } & : 1217 \text { jiwa } \\ \text { Jumlah } & : 2453 \text { jiwa }\end{array}$

Keadaan aparatur Desa Mekarmukti terdiri dari Kepala Desa, Sekeretaris Desa, Kaur Ekbang, Kaur Perencanaan, Kaur Pemerintahan, Kaur TU dan Umum, Kaur Keuangan, Kaur Kesra dan pelaksanana wilayah Dusun 1,2 dan 3 dengan sususan selengkapnya sebagai berikut :

Tabel 3

\begin{tabular}{cll}
\begin{tabular}{c} 
Susunan Aparatur Pemerintahan Desa Mekarmukti Tahun \\
\cline { 2 - 3 } NO
\end{tabular} & JABATAN & NAMA \\
\hline 1 & Kepala Desa & Subagio \\
2 & Sekretaris Desa & Dita Mulyati \\
3 & Kaur Ekbang & Taryat \\
4 & Kaur Perencanaan & Deden \\
5 & Kaur Pemerintahan & Usman \\
6 & Kaur TU danUmum & Tina \\
7 & Kaur Keuangan & Yan-yan \\
8 & KaurKesra & Rahmat \\
9 & Kadus Ciliang 1 & Jojo \\
10 & Kadus Ciliang 2 & Wiwi \\
11 & Kadus Citunggul & Ase \\
\hline & Sumber: (Desa Mekarmukti, 2019)
\end{tabular}

Data pendidikan Aparatur Desa Mekarmukti adalah sebagai berikut: 
Tabel 4

Keadaan Perangkat Desa Mekarmukti

Berdasarkan Pendidikan Tahun 2019

\begin{tabular}{|l|l|l|}
\hline NO & PENDIDIKAN & JUMLAH \\
\hline 1 & Sarjana & - \\
\hline 2 & Diploma & - \\
\hline 3 & SLTA & 8 \\
\hline 4 & SLTP & 3 \\
\hline 5 & SD & - \\
\hline \multicolumn{2}{|l|}{ JUMLAH } & 11 \\
\hline
\end{tabular}

Sumber: (Desa Mekarmukti, 2019)

Minimnya sumber daya manusia yang berpendidikan sarjana bagi Aparatur Desa Mekarmukti sangat berpengaruh terhadap pemahaman administrasi pada organisasi yang ada di Desa Mekarmukti. Salah satunya adalah Organisasi BUMDes dimana salah satu pertimbangan yang harus diperhatikan untuk mendirikan BUMDes agar mampu menghasilkan keluaran berupa kesejahteraan masyarakat adalah Sumber Daya Manusia.

Hal ini sesuai dengan yang disampaikan oleh Sekretaris Desa Mekarmukti bahwa secara kepengurusan BUMDes telah terbentuk tetapi masih belum bisa berjalan mengingat pemahaman para pengurus tentang pengelolaannya masih rendah. Perlu tindak lanjut dari Pemerintah Kabupaten Sumedang melalui DPMPD untuk memberikan penyuluhan tentang tata kelola BUMDes. Oleh karena itu, dengan adanya kegiatan KKN STIA Sebelas April Sumedang diharapkan mampu memfasilitasi kegiatan tersebut untuk membantu masyarakat Desa Mekarmukti dalam rangka peningkatan kesejahteraan secara ekonomi, dan kemandirian secara organisasi pada tatanan pemerintahan desa.

\section{METODE PELAKSANAAN}

Dengan lokasi yang cukup jauh dari pusat kota Kabupaten dan lahan yang dialokasikan sebagai lahan pertanian sangat dominan, tidak mengherankan jika mata pencaharian penduduk Desa Mekarmukti didominasi oleh sektor pertanian yang didukung oleh lahan pertanian berupa lahan pesawahan dan lahan perkebunan serta ladang. Lahan pesawahan di Desa Mekarmukti masih menggunakan sistem pengairan non teknis. Lahan pesawahannya menghasilkan produk utama berupa padi dengan produktivitas yang cukup. Selain itu dihasilkan juga beberapa jenis palawija seperti ubi kayu. Lahan perkebunan di Desa Mekarmukti menghasilkan berbagai jenis buah-buahan seperti alpukat, mangga, pisang dan petai. 


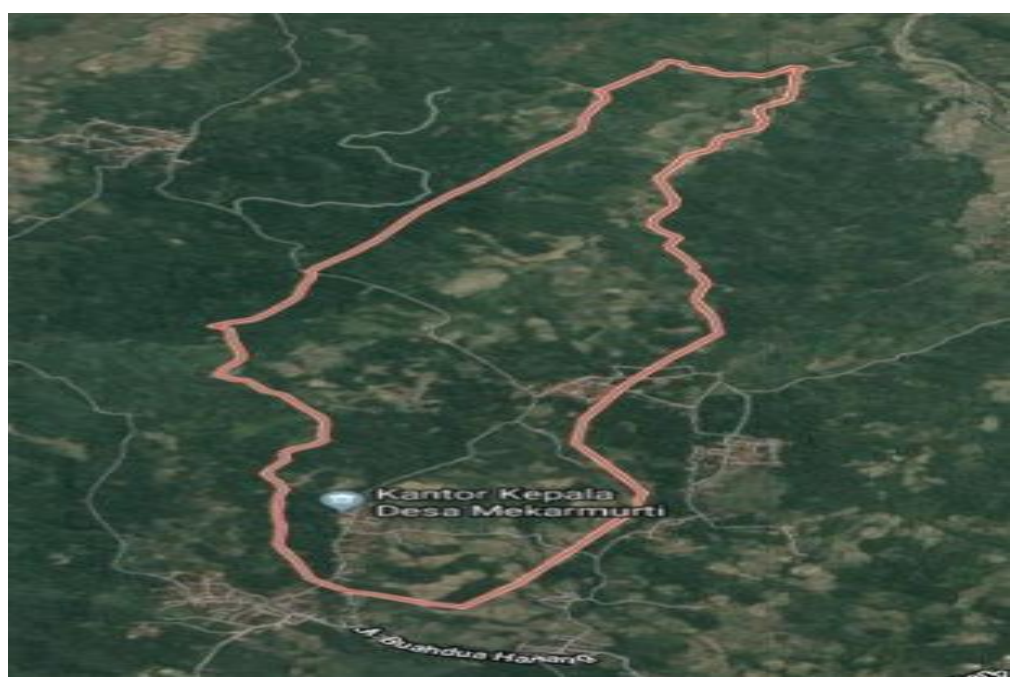

Gambar 1

Lokasi Desa Mekarmukti

Sumber: (Google Map, 2019)

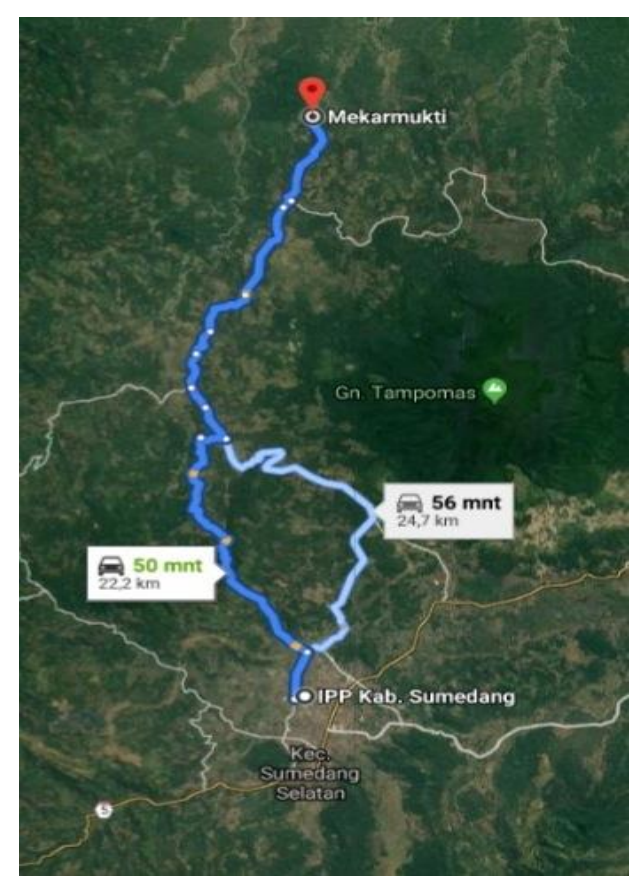

Gambar 2

Jarak Desa Mekarmukti ke Pusat Pemerintahan Kabupaten Sumedang Sumber: (Google Map, 2019)

Mengingat kebanyakan mata pencaharian penduduk Desa Mekarmukti adalah petani, maka untuk meningkatkan kesejahteraan masyarakat dan kemandirian desa, yang diupayakan oleh Pemerintah Desa Mekarmukti salah satunya adalah melalui BUMDes.

Untuk memfasilitasi keinginan Pemerintah Desa tersebut, maka disusunlah waktu pelaksanaan penyuluhan bagi pengurus BUMDes sebagai bagian dari pelaksanaan kegiatan Kuliah Kerja Nyata STIA Sebelas April Sumedang dengan tahapan sebagai berikut: 
Edi Setiawan \& Amelia Lestari Fauzy, Penyuluhan Pengurus Bumdes untuk Meningkatkan Kesejahteraan Masyarakat Desa Mekarmukti Kecamatan Buahdua Kabupaten Sumedang

1. Koordinasi dengan Dinas Pemberdayaan Masyarakat dan Pemerintahan Desa (DPMPD) Kabupaten Sumedang untuk menentukan waktu dan nara sumber pada kegiatan penyuluhan yang disepakati pada tanggal 29 Agustus 2019. Nara sumber adalah Harun Mulyana TW, S.Sos. Kepala Seksi Bina Administrasi dan Penataan Desa Bidang Pemerintahan Desa Dinas PMD Kabupaten Sumedang.

2. Konfirmasi kepada Pemerintahan Desa Mekarmukti tentang pelaksanaan Penyuluhan.

3. Persiapan administrasi kegiatan berupa surat-menyurat untuk pengurus BUMDes dan para tokoh Masyarakat Desa.

4. Pelaksanaan kegiatan disepakati pada Hari Kamis, 29 Agustus 2019 Pukul 09.00 sampai dengan 12.00 WIB.

Materi penyuluhan disampaikan oleh Bapak Harun Mulyana TW, S.Sos. sebagai Kepala Seksi Bina Administrasi dan Penataan Desa Bidang Pemerintahan Desa Dinas PMD Kabupaten Sumedang dengan peserta yang terdiri dari seluruh pengurus BUMDes Mekarmukti, Ketua BPD dan beberapa tokoh masyarakat Desa Mekarmukti.

Pada prinsipnya, bekerja bersama masyarakat adalah metode yang dipakai untuk lebih menerapkan prinsip partisipatif dan kemandirian bagi pengurus Bumdes. Diharapkan dari metode tersebut dapat terjalin komunikasi dan kerjasama yang lebih baik antara Pemerintah Desa, Pengurus BUMDes Mekarmukti dan Dinas PMD Kabupaten Sumedang sehingga keberadaan BUMDes benar-benar bisa memberikan kontribusi yang positif untuk kesejahteraan dan kemandirian masyarakat Desa Mekarmukti.

\section{HASIL DAN PEMBAHASAN}

Dengan dilaksanakannya kegiatan Penyuluhan bagi Pengurus BUMDes melalui model Kuliah Kerja Nyata-Pengabdian Pada Masyarakat (KKN-PPM), pola pikir para pengurus beserta Aparat Desa Mekarmukti menjadi lebih terbuka. Konsep kemajuan BUMDes sangat tergantung dari motivasi dari pengurus itu sendiri. Unit usaha bisa dibentuk dari apa yang ada di sekitar desa dan berdasar pada kebutuhan masyarakat desa.

Para pengurus dan Pemerintahan desa yang selama ini kebingungan dengan masalah modal, kini telah mengetahui bahwa modal usaha BUMDes bisa berasal dari:

1. APB Desa yang dapat berasal dari:

a. Hibah dari pihak swasta, lembaga sosial ekonomi kemasyarakatan dan/atau 
lembaga donor yang disalurkan melalui mekanisme APB Desa;

b. Bantuan Pemerintah, Pemerintah Daerah Provinsi, dan Pemerintah Daerah Kabupaten/Kota yang disalurkan melalui mekanisme APB Desa;

c. Kerjasama usaha dari pihak swasta, lembaga sosial ekonomi kemasyarakatan dan/atau lembaga donor yang dipastikan sebagai kekayaan kolektif Desa dan disalurkan melalui mekanisme APB Desa;

d. Asset Desa yang diserahkan kepada APB Desa sesuai dengan ketentuan peraturan perundang-undangan tentang Aset Desa.

2. Penyertaan modal masyarakat Desa; berasal dari tabungan masyarakat dan atau simpanan.

Jenis usaha yang bisa dilakukan dalam pengelolaan BUMDes diantaranya:

a. Usaha bersama (holding) yang bisa berupa air minum desa, usaha listrik desa, lumbung pangan;

b. Usaha Sosial;

c. Penyewaan: alat transportasi, perkakas pesta, gedung pertemuan

d. Usaha Keuangan: simpan pinjam

e. Usaha Perdagangan: Pasar Desa

f. Usaha Perantara (brokering)

g. Dan lain-lain yang bisa dimanfaatkan oleh berdasarkan kebutuhan masyarakat baik di Desa Mekarmukti maupun di Desa lainnya yang memungkinkan untuk dijadikan sasaran usaha.

Dari jenis usaha tersebut ditetapkan untuk dicoba dalam hal penyewaan alat-alat pesta yang dimulai dari penyewaan kursi dengan modal awal dari APB Desa.

Motivasi pengurus BUMDes semakin meningkat ketika disampaikan persentasi pembagian bagi hasil usaha BUM Desa_berdasarkan ketentuan yang diatur dalam Anggaran Dasar/Anggaran Rumah Tangga BUM Desa dengan mengacu kepada Perdes yang dicontohkan sebagai berikut:

Besarnya bagi hasil usaha BUMDes setiap tahun dipergunakan untuk :
a. Pemupukan modal usaha : $30 \%$
b. Pendapatan Asli Desa (PAD) : $30 \%$
c. Pendidikan pelatihan pengurus : $10 \%$
d. Penasehat : $5 \%$
e. Pelaksana operasional $\quad: 10 \%$ 
Edi Setiawan \& Amelia Lestari Fauzy, Penyuluhan Pengurus Bumdes untuk Meningkatkan Kesejahteraan Masyarakat Desa Mekarmukti Kecamatan Buahdua Kabupaten Sumedang
f. Pengawas
: $5 \%$
g. Dll.....
:.... \% berdasarkan kesepakatan pengurus.

Program Penyuluhan Pengurus BUMDes ini merupakan program utama dari program pendukung pada kegiatan KKN-PPM STIA Sebelas April Sumedang. Adapun program atau kegiatan pendukung PKM lainnya adalah berupa pelaksanaan kegiatan administrasi secara sempit yang dilaksanakan pada aspek lembaga kemasyarakatan dengan titik sentral peningkatan rakyat pedesaan dalam wujud kegiatan sebagai berikut:
a. Piket Harian Desa.
b. Membantu pentaan arsip dan ketatausahaan.
c. Penggalian Potensi Unggulan Desa Mekrmukti.
d. Penataan Manajemen Perkantoran Desa.
e. Pembuatan Berbagai Surat.
f. Pembuatan Laporan Keuangan.
g. Kunjungan dan silaturahmi dengan perangkat Desa Mekarmukti dan masyarakat desa.
h. Sosialisasi ke SD.
i. Membantu kegiatan posyandu.
j. Mengikuti kegiatan senam pada hari jum'at.
k. Mengikuti kegiatan pengajian rutinan
l. Mengikuti acara pameran setiap desa di kecamatan.
m. Berpartisipasi dalam merayakan HUT RI.
n. Mengikuti operasi bersih pada hari jum'at.

Adanya program tambahan atau biasa disebut sebagai program penunjang adalah sebagai implementasi dari pemahaman administrasi secara sempit yaitu berupa ketatausahaan. Sementara program utama atau bidang garapan utama adalah berupa administrasi secara luas dalam arti kerjasama yang dalam hal ini adalah berupa Program Kegiatan Penyuluhan Pengurus BUMDes Mekarmukti Untuk Meningkatkan Kesejahteraan Masyarakat Desa Mekarmukti Kecamatan Buahdua Kabupaten Sumedang.

\section{SIMPULAN}

Program Kuliah Kerja Nyata STIA Sebelas April Sumedang memuat 2 (dua) bidang garapan yaitu Bidang Garapan Utama dan Bidang Garapan Penunjang Profesi. Kedua bidang garapan tersebut telah berhasil dilaksanakan dengan baik.

Pada bidang garapan penunjang profesi telah mampu meningkatkan pemahaman aparat desa mengenai administrasi secara sempit pada tatanan pengelolaan administrasi 
desa dimana arsip desa, surat masuk dan surat keluar serta ekspedisi surat telah lebih tertib dari sebelumnya.

Pada bidang garapan utama yaitu Pelaksanaan penyuluhan bagi pengurus BUMDes mendapat respon yang sangat baik khususnya dari pengurus BUMDes dan Pemerintahan Desa Mekarmukti. Terbukanya pemahaman tentang pendirian dan pengelolaan BUMDes dapat meningkatkan motivasi yang semakin tinggi untuk mengelola BUMDes dalam rangka meningkatkan kesejahteraan masyarakat desa.

Selain daripada itu, jalinan kerjasama antara Pemerintah Desa Mekarmukti dengan Pemerintah Daerah Kabupaten Sumedang khususnya Dinas Pemberdayaan Masyarakat Desa (DPMD) semakin erat.

Permasalahan yang ditemukan dari hasil observasi awal telah mampu diselesaikan yaitu meningkatnya kualitas sumber daya manusia khususnya pengurus BUMDes mengenai tata kelola dalam mewujudkan BUMDes yang maju serta mandiri yang mampu memberikan kesejahteraan bagi masyarakat Desa Mekarmukti.

Capaian yang diperoleh tersebut tidak lepas dari beberapa hal yang masih perlu ditindaklanjuti diantaranya adalah perlunya pelatihan khusus bagi para pengurus dalam tatanan administrasi dan manajemen keuangan BUMDes agar tercapai kesempurnaan kepengurusan BUMDes Mekarmukti yang lebih baik.

\section{DAFTAR PUSTAKA}

BPS Kabupaten Sumedang. (2018). Kabupaten Sumedang Dalam Angka Sumedang Regency in Figures 2018. Bandung: CV Setia Abadi.

Desa Mekarmukti. (2019). Rencana Pembangunan Jangka Menengah Desa Mekarmukti. Sumedang: Desa Mekarmukti.

Google Map. (2019). desa mekarmukti sumedang. Retrieved September 23, 2019, from https://www.google.com/maps/place/Mekarmukti,+Buahdua,+Kabupaten+Sumedang,+Jawa+Bara t/@-

6.6886896,107.9044903,14z/data=!3m1!4b1!4m5!3m4!1s0x2e69293db86140b1:0xb97bf2ee1a89 $631 \mathrm{e} ! 8 \mathrm{~m} 2$ !3d-6.6879584!4d107.9205937?hl=id

Jabarprov.go.id. (2017). Akhir Tahun 2017, Seluruh Desa di Sumedang Dituntut Mampu Membentuk $\begin{array}{lllll}\text { BUMDes. } & \text { Retrieved } & \text { September } & \text { 9, 2019, from }\end{array}$ https://jabarprov.go.id/index.php/news/25729/2017/11/08/Akhir-Tahun-2017-Seluruh-Desa-diSumedang-Dituntut-Mampu-Membentuk-BUMDes

Peraturan Bupati Sumedang. (2018). PETUNJUK TEKNIS PENDIRIAN, PENGELOLAAN DAN PEMBUBARAN BADAN USAHA MILIK DESA NOMOR 22 TAHUN 2018. Sumedang: Pemerintah Daerah Kabupaten Sumedang.

Silalahi, U. (2011). Studi Tentang Ilmu Administrasi. Bandung: Sinar Baru Algensindo. 